\title{
New Group Contribution Method for Predicting the Critical Pressures of Fatty Acids and Triglycerides
}

\author{
Charles Otobrise $^{1,}$, , Kenneth Osondu Monago ${ }^{2}$ \\ ${ }^{1}$ Department of Chemistry, Delta State University, Abraka, Nigeria \\ ${ }^{2}$ Department of Pure and Industrial Chemistry, University of Port - Harcourt, Choba, Port- Harcourt, Nigeria \\ Email address: \\ otobrisec@delsu.edu.ng (C. Otobrise)
}

\section{To cite this article:}

Charles Otobrise, Kenneth Osondu Monago. New Group Contribution Method for Predicting the Critical Pressures of Fatty Acids and Triglycerides. International Journal of Computational and Theoretical Chemistry. Vol. 3, No. 6, 2015, pp. 45-49.

doi: $10.11648 /$ j.ijctc. 20150306.11

\begin{abstract}
A new and useful method for evaluating and predicting the critical pressures $\left(P_{c}\right)$ of $\mathrm{n}$-fatty acids and triglycerides was developed in this study. Logarithmic equations which required critical temperature $\left(T_{c}\right)$ and normal boiling temperature $\left(T_{b}\right)$ were proposed for the fatty acids and their corresponding triglycerides. The method predicted with good accuracy the critical pressures $\left(P_{c}\right)$ of the $\mathrm{n}$-fatty acids, even without the input of the compressibility factor $\left(\Delta Z_{b}\right)$. The deviations of predicted critical pressures from experimental values were between (0-7)\%, except for Caproic and Caprylic acids; where the method under predicted the critical pressures with deviations of $-6.64 \%$ and $-11.31 \%$ respectively. Experimental $P_{c}$ values for the triglycerides were not available in the open literature for comparison.
\end{abstract}

Keywords: Critical Pressures, n-Fatty Acids, Triglycerides, Enthalpies of Vapourisation, Trouton's Rule, Clausius-Clapeyron Equation

\section{Introduction}

The implementation of many equation of state methods, require critical properties of organic compounds [1]. It is not always possible to find experimental values in the literature and since measurement is expensive and time consuming or sometimes even difficult or impossible, estimation/group contribution methods, which need only the structural information of the molecule are generally of great value [2 4].

A Group Contribution method uses the principle that some simple aspects of the structures of chemical components are always the same in many different molecules. The smallest common constituents are the atoms and the bonds. By using group or atom properties, the physical properties of pure compounds and mixtures can be predicted. [5 - 8]. Kreglenski and Zwolinski [9], Tsonopoulus [10], Gray et.al. [11], Teja et.al. [12], and Magoulas and Tassios [13], proposed Group Contribution methods that correlated critical properties and normal boiling point to the number of carbon atoms in the molecule for homologous series, such as normal alkanes and alkanols. These correlations have been found to be accurate [5]. However, their range of application was questioned by
Kreglenski and Zwolinski [9] and Tsonopoulos and Tan [14].

There are a large number of group contribution methods for the estimation of physical Properties [2], in particular the critical pressure, available in literature. In summary, current methods cannot provide a simple and accurate estimation of the critical pressure across all compounds. Most methods have high average absolute deviations from experimental values available in literature. Hence, the objective of this study was to develop a reliable group contribution estimation method for the prediction of the critical pressures of fatty acids and esters (triglycerides). A data base of this sort is of utmost significance in the analysis and design of plants for separation and purification of vegetable oils.

\section{Experimental Data}

We did not carry out any experimental measurements ourselves, this work is purely theoretical and computational. However, experimental thermodynamic and critical properties of the fatty acids were obtained from the works of Gokel [15]; Cunico et al [3]; Majer and Svoboda [16]; Ruzicka and Majer [17]; Sales-Cruz et al [18]. 


\section{Development of the New Method}

Many of the vapour pressure equations that are used in industry today have their roots in the Clausius-Clapeyron equation. Equation (1) is the differential form of the Clausius -Clapeyron equation.

$$
\frac{\partial P}{\partial \mathrm{T}}=\frac{\Delta H P}{R T^{2}}
$$

Deviations from the ideal gas law are expressed in terms of the compressibility factor $(Z)$.

$$
Z=\frac{P V}{R T}
$$

In the case of vapourisation or sublimation, we can assume that the change in compressibility factor is unity. Hence;

$$
\Delta Z=Z_{g}-Z_{l}=Z_{g}-Z_{s}=1
$$

We can then write equation (3) as;

$$
\frac{\partial P}{\partial \mathrm{T}}=\frac{\Delta H P}{\Delta Z R T^{2}}
$$

Rearranging equation (4) gives;

$$
\frac{\partial P}{P}=\frac{\Delta H}{\Delta Z R}\left(\frac{\partial T}{T^{2}}\right)
$$

Equation (5) can be expressed logarithmically as;

$$
\partial \ln P=\frac{\Delta H}{\Delta Z R}\left(\frac{\partial T}{T^{2}}\right)
$$

If we assume that $H$ docs not vary with tempcrature and pressure; equation (6) may be simplified to give;

$$
\partial \ln P=\frac{\Delta H_{b}}{\Delta Z_{b} R} \partial\left(\frac{1}{T}\right)
$$

Integrating equation (7) will give rise to a two-component, modified Clausius-Clapeyron equation. The enthalpy of vapourisation and the compressibility factor for the fluid is at the boiling point $\Delta H_{b}$ and $\Delta Z_{b}$ respectively.

$$
\begin{aligned}
& \int_{P_{b}}^{P_{c}} \partial \ln P=\frac{\Delta H_{b}}{\Delta Z_{b} R} \int_{T_{b}}^{T_{c}} \partial\left(\frac{1}{T}\right) \\
& \ln P_{c}-\ln P_{b}=\frac{\Delta H_{b}}{\Delta Z_{b} R}\left(\frac{1}{T_{b}}-\frac{1}{T_{c}}\right)
\end{aligned}
$$

From Trouton's rule

$$
\Delta H_{b}=T_{b} \Delta S_{b}
$$

at the boiling point

Substituting for $\Delta H_{b}$ in equation (9) we have:

$$
\ln \left(\frac{P_{c}}{P_{b}}\right)=\frac{T_{b} \Delta S_{b}}{\Delta Z_{b} R}\left(\frac{T_{c}-T_{b}}{T_{b} T_{c}}\right)
$$

Hence,

$$
\ln \left(\frac{P_{c}}{P_{b}}\right)=\frac{\Delta S_{b}}{\Delta Z_{b} R}\left(\frac{T_{c}-T_{b}}{T_{c}}\right)
$$

If pressure is expressed in units of atmospheres, then $P_{b}=1 \mathrm{~atm}$. Consequently equation (12) can then be written as;

$$
\ln \left(P_{c} /(a t m)\right)=\frac{\Delta S_{b}}{R \Delta Z_{b}}\left(\frac{T_{c}-T_{b}}{T_{c}}\right)
$$

As a first approximation, we take $P_{b}=1$. Hence equation (13) becomes;

$$
\ln \left(P_{c} /(a t m)\right)=\frac{\Delta S_{b}}{R}\left(\frac{T_{c}-T_{b}}{T_{c}}\right)
$$

The Ambrose [19] parameter $X$ is given as;

$$
X=\frac{T_{b}}{T_{c}-T_{b}}
$$

Substituting $X$ into equation (14) will give rise to a basic equation for predicting $P_{c}$

$$
\ln \left(P_{c} /(a t m)\right)=\frac{\Delta S_{b}}{R}\left(\frac{1}{1+X}\right)
$$

Hence,

$$
(1+X) \ln \left(P_{c} /(a t m)\right)=\frac{\Delta S_{b}}{R}
$$

Equation (17) is the basic Group Contribution approach for predicting $P_{c}$ for n-alkanes [20]. A plot of $(1+\mathrm{X}) \ln P_{c}$ versus number of carbon atoms for n-alkanes gave a straight line graph, whose slope accounted for the contributions of the $-\mathrm{CH}_{3}$ and $-\mathrm{CH}_{2}$ - groups. In order to obtain the contribution of the $-\mathrm{COOH}$ group in n-fatty acids and $-\mathrm{CH}=\mathrm{CH}-$ group in unsaturated n-fatty acids, a modification of equation (17) was necessary. The modification gave rise to two new equations viz.

$$
(1+X) \ln \left(P_{c} /(a t m)\right)=\left(\frac{A_{1}+A_{2}}{2.5}\right)+W_{1} N_{c}+W_{2}
$$

(For saturated n-fatty acids) and

$$
(1+X) \ln \left(P_{c} /(a t m)\right)=\left(\frac{A_{1}+A_{2}}{2.7}\right)+W_{1} N_{c}+W_{2}-D W_{3}
$$

(For unsaturated n-fatty acids)

A further modification of equations (18) and (19) gave rise to two new equations, accounting for the contributions of the - $\mathrm{COO}-$ and $-\mathrm{C}$ H groups in each triglyceride. Equations (20) and (21) were proposed for the prediction of $P_{c}$ for triglycerides of saturated and unsaturated fatty acids respectively. 


$$
\begin{aligned}
& (1+X) \ln P_{c}=\frac{\left(\frac{A_{1}+A_{2}+A_{3}}{1.3}\right)+W_{1}\left(N_{c}-4\right)+3 V_{1}+V_{2}}{W_{1}\left(N_{c}-4\right)} \\
& (1+X) \ln P_{c}=\frac{\left(\frac{A_{1}+A_{2}+A_{3}}{1.3}\right)+W_{1}\left(N_{c}-4\right)+3 V_{1}+V_{2}-D W_{3}}{W_{1}\left(N_{c}-4\right)}
\end{aligned}
$$

$A_{1}, A_{2}$ and $A_{3}$ in equations $(18-21)$ are constants with values of $9.62,18.60$ and 1.50 respectively. $D=$ number of $-\mathrm{CH}=\mathrm{CH}-$ groups in each molecule of the unsaturated fatty acid. $N_{c}=$ number of carbon atoms. Table 1 contains the values of other parameters in equations $(18-21)$.

Table 1. Contributions of Groups to the Prediction of $P_{c}$.

\begin{tabular}{lll}
\hline Symbol & Group & Contribution \\
\hline$W_{I}$ & $-\mathrm{CH}_{2}-$ & 0.096 \\
$W_{I}$ & $-\mathrm{CH}_{3}$ & 0.096 \\
$W_{2}$ & $-\mathrm{COOH}$ & 0.316 \\
$W_{3}$ & $-\mathrm{CH}=\mathrm{CH}-$ & 0.206 \\
$V_{I}$ & $-\mathrm{COO}-$ & 0.203 \\
$V_{2}$ & $-\mathrm{CH}$ & 0.014 \\
\hline
\end{tabular}

\section{Results and Discussion}

The experimental thermodynamic properties of the nfatty acids in this study are presented in Table 2 . Experimental properties for some of the fatty acids were not available in the literature. Experimental critical properties of the fatty acids that were available in the literature are shown in Table 3.

Table 2. Thermodynamic Properties of n-Fatty Acids.

\begin{tabular}{llllcc}
\hline Name & $\boldsymbol{N}_{\boldsymbol{c}}$ & $\begin{array}{l}\Delta \boldsymbol{H}_{\text {(vap) } \mathbf{b}} / \mathbf{K} \\
\mathbf{J m o l}^{-1}\end{array}$ & $\boldsymbol{T}_{\boldsymbol{b}} / \mathbf{K}$ & $\begin{array}{l}\Delta \boldsymbol{S}_{\text {(vap) }} / \mathbf{K} \\
\mathbf{J m o l}^{-1}\end{array}$ & $\boldsymbol{\Delta \boldsymbol { S } _ { \text { (vap) } } / \mathbf { R }}$ \\
\hline Caproic Acid & 6 & $64.66^{\mathrm{a}}$ & $478.70^{\mathrm{a}}$ & 0.1351 & 16.2496 \\
Caprylic Acid & 8 & $70.02^{\mathrm{a}}$ & $512.30^{\mathrm{a}}$ & 0.1367 & 16.4395 \\
Capric Acid & 10 & N/A & $541.92^{\mathrm{b}}$ & - & - \\
Lauric Acid & 12 & N/A & $571.40^{\mathrm{b}}$ & - & - \\
Myristic Acid & 14 & N/A & $599.00^{\mathrm{b}}$ & - & - \\
Palmitic Acid & 16 & N/A & $622.30^{\mathrm{b}}$ & - & - \\
Stearic Acid & 18 & N/A & $648.10^{\mathrm{b}}$ & - & - \\
Oleic Acid & 18 & $67.40^{\mathrm{c}}$ & $633.00^{\mathrm{c}}$ & 0.1065 & 12.8070 \\
Linoleic Acid & 18 & N/A & $624.10^{\mathrm{d}}$ & - & - \\
Linolenic Acid & 18 & N/A & $622.70^{\mathrm{d}}$ & - & - \\
\hline
\end{tabular}

Source: ${ }^{\mathrm{a}}$ Gokel, (2004); ${ }^{\mathrm{b}} \mathrm{Cunico}$ et.al, (2013); ${ }^{\mathrm{c}}$ Majer and Svoboda, (1985) and ${ }^{\mathrm{C}}$ Ruzicka and Majer, (1994); ${ }^{\mathrm{d}}$ Estimated from the Method of

Constantinou and Gani. N/A= Not available.

The critical pressures predicted by equations (18) and (19) and their deviations from experimental values are presented in Table 3. The deviations in Table 3 were calculated according to the relation:

$$
D=\frac{P_{c_{\text {(calc.) }}}-P_{c_{(\text {exp } .)}}}{P_{c_{\text {(exp. })}}} \times 100
$$

Table 3. Experimental Critical Temperatures $\left(T_{c}\right)$ and Pressures $\left(P_{c}\right)$ of Fatty Acids.

\begin{tabular}{llll}
\hline Name & $\boldsymbol{N}$ & $\boldsymbol{T}_{\boldsymbol{c}}(\mathbf{e x p}) / \mathbf{K}$ & $\boldsymbol{P}_{\boldsymbol{c}}(\mathbf{e x p}.) / \mathbf{a t m}$. \\
\hline Caproic Acid & 6 & $663.00^{\mathrm{a}}$ & $33.33^{\mathrm{a}}$ \\
Caprylic Acid & 8 & $694.26^{\mathrm{a}}$ & $27.43^{\mathrm{a}}$ \\
Capric Acid & 10 & $726.00^{\mathrm{a}}$ & $22.21^{\mathrm{a}}$ \\
Lauric Acid & 12 & $743.43^{\mathrm{a}}$ & $18.43^{\mathrm{a}}$ \\
Myristic Acid & 14 & $765.19^{\mathrm{a}}$ & $16.23^{\mathrm{a}}$ \\
Palmitic Acid & 16 & $785.22^{\mathrm{a}}$ & $14.49^{\mathrm{a}}$ \\
Stearic Acid & 18 & $805.09^{\mathrm{a}}$ & $13.10^{\mathrm{a}}$ \\
Oleic Acid & 18 & $795.17^{\mathrm{b}}$ & N/A \\
Linoleic Acid & 18 & $793.68^{\mathrm{b}}$ & N/A \\
Linolenic Acid & 18 & $792.18^{\mathrm{b}}$ & N/A \\
\hline
\end{tabular}

Source: a Cunico et.al, (2013) and ${ }^{\mathrm{b} S}$ Sales-Cruz et.al, (2010). *Estimated by the Method of Constantinou and Gani.

The deviations of predicted critical pressures from experimental values were between $(0-7) \%$, except for Caproic acid and Caprylic acid; where the method under predicted the critical pressures with deviations of $-6.64 \%$ and $-11.31 \%$ respectively from experimental $P_{c}$ values. It is pertinent to note that the predictive capability of our equation improved with increase in chain length of the fatty acids.

Table 4. Predicted $P_{c}$ of $n$-Fatty Acids and their Deviations from Experimental Values.

\begin{tabular}{llll}
\hline Name & $\boldsymbol{N}$ & $\boldsymbol{P}_{\boldsymbol{c}}$ (calc.)/atm. & Deviations (\%) \\
\hline Caproic Acid & 6 & 29.56 & -11.31 \\
Caprylic Acid & 8 & 25.61 & -6.64 \\
Capric Acid & 10 & 23.69 & 6.66 \\
Lauric Acid & 12 & 18.94 & 2.77 \\
Myristic Acid & 14 & 16.55 & 1.97 \\
Palmitic Acid & 16 & 14.73 & 1.66 \\
Stearic Acid & 18 & 13.21 & 0.84 \\
Oleic Acid & 18 & 12.26 & - \\
Linoleic Acid & 18 & 13.22 & - \\
Linolenic Acid & 18 & 12.69 & - \\
\hline
\end{tabular}

Table 5 shows the $P_{c}$ values for the triglycerides estimated with equations (20) and (21). As expected, $P_{c}$ decreased with increase in the number of carbon atoms. However, the $P_{c}$ predicted for trimyristin exhibited a slight deviation from this trend. This is attributable to the experimental boiling point found for trimyristin in the open literature. Experimental $P_{c}$ values were not found in the open literature for the triglycerides to serve as a basis for comparison.

The available data for the fatty acids and triglycerides have been used to investigate the capability of the method for $P_{c}$, developed in this study, to extrapolate higher carbon numbers of fatty acids and triglycerides. This assertion is illustrated in figures 1 and 2. In view of figures 1 and 2, one can expect the method developed in this study to provide reliable $P_{c}$ values for a wide range of fatty acids and triglycerides. However, the unavailability of experimental data of $P_{c}$ for triglycerides does not permit us to make a definite statement on the uncertainties to predicted $P_{c}$ for the esters. 
Table 5. Predicted $P_{c}$ of Triglycerides.

\begin{tabular}{llll}
\hline Common Name & Formula & Nc & Pc/atm. \\
\hline Tricaproin & $\mathrm{C}_{21} \mathrm{H}_{38} \mathrm{O}_{6}$ & 21 & 10.51 \\
Tricaprylin & $\mathrm{C}_{27} \mathrm{H}_{50} \mathrm{O}_{6}$ & 27 & 7.31 \\
Tricaprin & $\mathrm{C}_{33} \mathrm{H}_{62} \mathrm{O}_{6}$ & 33 & 6.70 \\
Trilaurin & $\mathrm{C}_{39} \mathrm{H}_{74} \mathrm{O}_{6}$ & 39 & 5.67 \\
Trimyristin & $\mathrm{C}_{45} \mathrm{H}_{86} \mathrm{O}_{6}$ & 45 & 6.20 \\
Tripalmitin & $\mathrm{C}_{51} \mathrm{H}_{98} \mathrm{O}_{6}$ & 51 & 5.31 \\
Tristearin & $\mathrm{C}_{57} \mathrm{H}_{110} \mathrm{O}_{6}$ & 57 & 4.76 \\
Triolein & $\mathrm{C}_{57} \mathrm{H}_{104} \mathrm{O}_{6}$ & 57 & 4.56 \\
Trilinolein & $\mathrm{C}_{57} \mathrm{H}_{98} \mathrm{O}_{6}$ & 57 & 4.38 \\
Trilinolenin & $\mathrm{C}_{57} \mathrm{H}_{92} \mathrm{O}_{6}$ & 57 & 4.20 \\
\hline
\end{tabular}

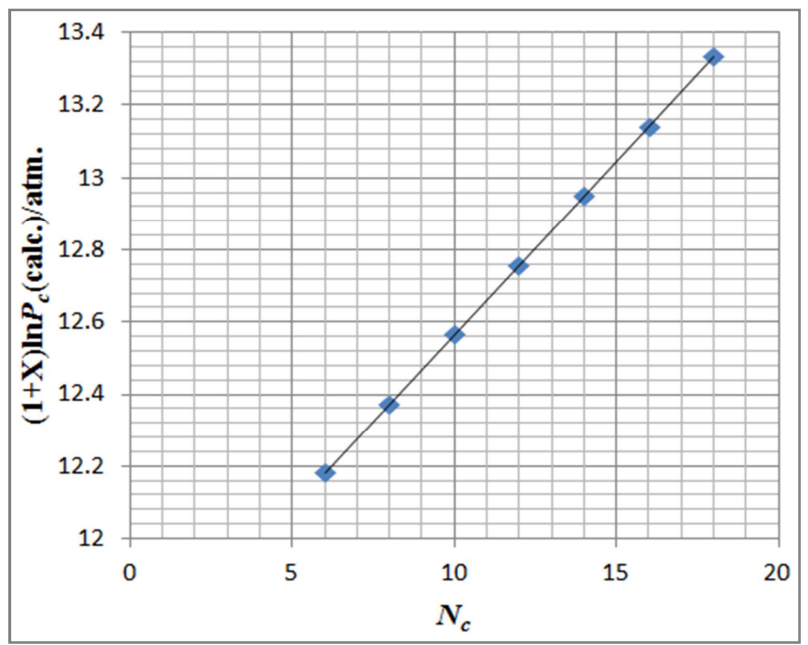

Fig. 1. A Plot of $(1+X) \ln P_{c}\left(\right.$ calc.) Versus $N_{c}$ for $n$-Fatty Acids.

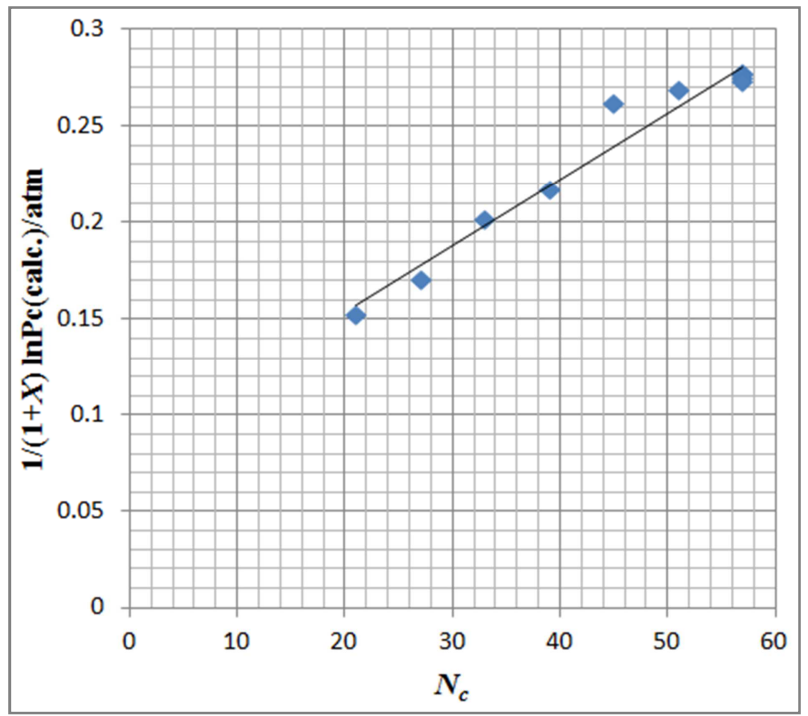

Fig. 2. A Plot of $1 /(1+X) \ln P_{c}$ Versus $N_{c}$ for the Triglycerides.

\section{Conclusion}

The critical pressures of the n-fatty acids and triglycerides were predicted through a new Group Contribution method. The method was based on Group Contribution and the traditional temperature-dependence correlations. The impute parameters were critical temperature $\left(T_{c}\right)$, normal boiling temperature $\left(T_{b}\right)$, enthalpies of vapourisation at the boiling temperatures of the $\mathrm{n}$-fatty acids and triglycerides. The results were compared with experimental critical pressures of the $\mathrm{n}$-fatty acids; unfortunately, no experimental data were found for the triglycerides in the open literature. The results were generally in good agreement with experimental $P_{c}$ values cited in the literature. The paucity of experimental data notwithstanding, we consider that the results for fatty acids and triglycerides are enough to validate the method.

\section{References}

[1] K.O. Monago and C. Otobrise, (2010) Estimation of Pure Component Properties of Fatty Acids and Esters, J. Chem. Soc. Nigeria, 35, (2), p143.

[2] Y. Nannoolal, (2004), Development of a Group Contribution Method for the Prediction of Normal Boiling Points of Nonelectrolyte Organic Compounds(M.Sc. Thesis), University of Kwazulu-Natal, Durban, South Africa.

[3] L.P. Cunico, R. Ceriani and R. Guirardello, (2013), Estimation of Physical Properties of Vegetable Oils and Biodiesel, Using Group Contribution Methods, Chemical Engineering Transactions, 32, 535-540.

[4] C. H. Fisher, (1989), Evaluation and Prediction of n Fatty Acid Critical Properties, JAOCS, 66, (8) 1158-1165.

[5] L. Constantinou and R. Gani, (1994), New Group Contribution Method for Estimating Properties of Pure Compounds, AIChE Journal, 40, (10), 1697 - 1710.

[6] F. O. Cedeño, M. M. Prieto and J. Xiberta, (2000), Measurements and Estimate of Heat Capacity for Some Pure Fatty Acids and Their Binary and Ternary Mixtures, J. Chem. Eng. Data.45, 64-69.

[7] J. Marrero and R. Gani, (2001), Group-Contribution Based Estimation of Pure Component Properties, Fluid Phase Equil. 183-184, 183-208.

[8] R. Gani, P. M. Harper and M. Hostrup, (2005), Automatic Creation of Missing Groups through Connectivity Index for Pure-Component Property Prediction, Ind. Eng. Chem. Res. $44,7262-7269$.

[9] A. Kreglenski and B. J. Zwolinski, (1961), A New Relation for Physical Properties of n-Alkanes and n-Alkyl Compounds, Journal of Physical Chemistry, 65, 1050-1054.

[10] C. Tsonopoulos, (1987), Critical Constants of Normal Alkanes from Methane to Polyethelene, AIChE Journal, 33, (12), 2080-2084.

[11] R. D. Jr. Gray, J. L. Heidman, R. D. Springer and C. Tsonopoulos, (1998), Characterization and Property Prediction for Heavy Petroleum and Synthesis Liquids, Fluid Phase Equilibrium, 53, 355-360.

[12] A. S. Teja, R. J. Lee, D. J. Rosenthal and M. Anselme, (1990), Correlation of the Critical Properties of Alkanes and Alkanols, Fluid Phase equilib. 56, 153-158.

[13] K. Magoulas and D. P. Tassios, (1990), Thermo physical Properties of n-Alkanes from $\mathrm{C}_{1}$ to $\mathrm{C}_{20}$ and their Prediction to Higher Ones, Fluid Phase Equilibr. 56, 119-123. 
[14] C. Tsonopoulos and Z. Tan, (1993): On the Continuity of the Gaseous and Liquid States (doctoral dissertation), Universiteit Leiden.

[15] G.W. Gokel, (2004), Dean's Handbook of Organic Chemistry, $2^{\text {nd }}$ Edition, McGraw-Hill Companies, Inc. U.S.A.

[16] V. Majer and V. Svoboda, (1985), Enthalpies of Vapourisation of Organic Compounds, Blackwell Scientific Publications, Oxford.

[17] K. Ruzicka and V. Majer, (1994), Simultaneous Treatment of Vapour Pressures and Related Thermal Data Between the Triple and Normal Boiling Point Temperatures for n-Alkanes $\mathrm{C}_{5}-\mathrm{C}_{20}$, J. Phys. Chem. Ref. Data 23, (1) 24.
[18] M. Sales-Cruz, G. Aca-Aca, O. Sanchez-Daza and T. LopezArenas, (2010), Predicting Critical Properties, Density and Viscosity of Fatty Acids, Triacylglycerols and Methyl Esters by Group Contribution Methods, $20^{\text {th }}$ European Symposium on Computer Aided Process Engineering, Elsevier B.V.

[19] D. Ambrose, (1978), Correlation and Estimation of Vapour Liquid Critical Properties: I Critical Temperatures of Organic Compounds, NPL Report Chem. 92, National Physical Laboratory, Teddington, UK.

[20] C. Otobrise and K.O. Monago, (2015), Group Contribution Method for Estimating the Critical Pressures of $\mathrm{C}_{1}-\mathrm{C}_{20} \mathrm{n}$ Alkanes, Scientia Africana, an International Journal of Pure \& Applied Sciences, 14, (1), 197-205. 